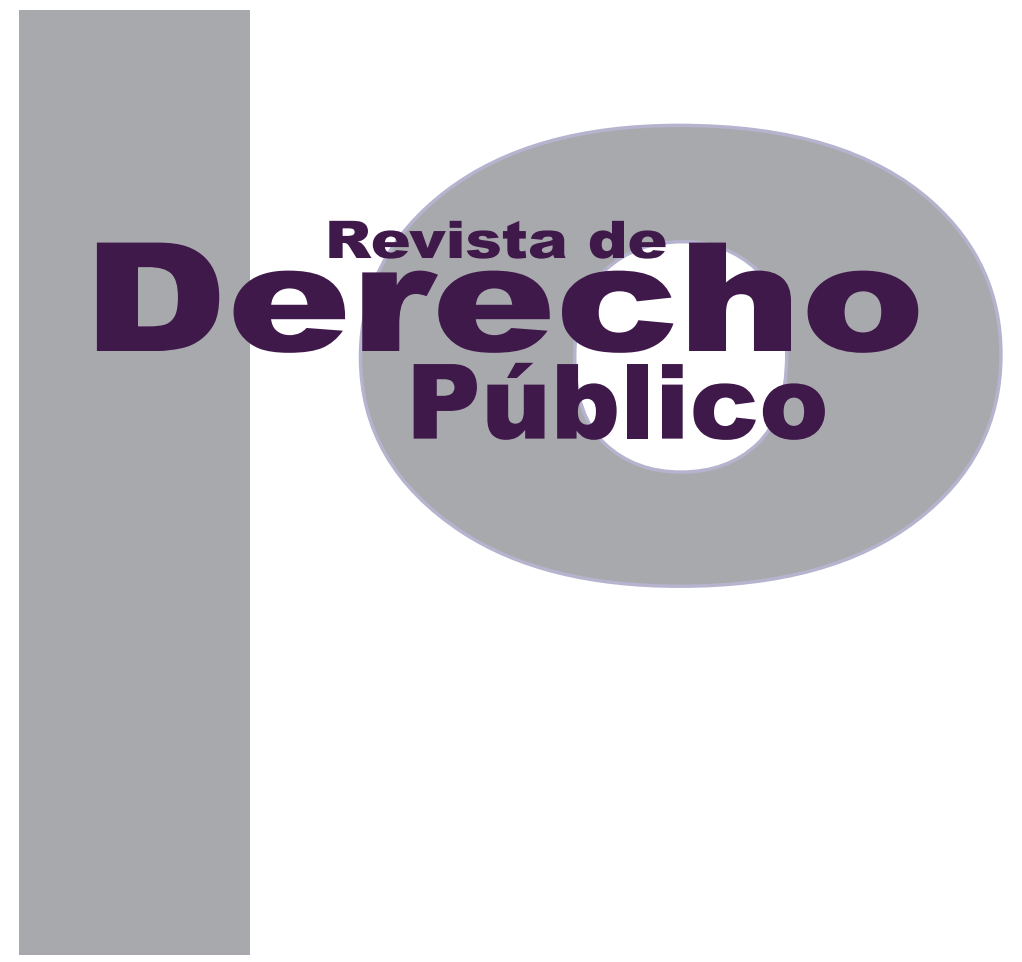

\title{
EL ARTÍCULO III DEL GATT: NORMA APLICABLE A LAS MEDIDAS COMERCIALES RESTRICTIVAS RELATIVAS A LOS MÉTODOS Y PROCESOS DE PRODUCCIÓN EN VIRTUD DEL PRINCIPIO DE DESARROLLO SOSTENIBLE
}

Francisco VillanUeva

Artículo de reflexión

Universidad de los Andes

Facultad de Derecho

Revista de Derecho Público N. ${ }^{\circ} 32$

Enero - Junio de 2014. ISSN 1909-7778 


\title{
El artículo III del GATT: norma aplicable a las medidas comerciales restrictivas relativas a los métodos y procesos de producción en virtud del principio de desarrollo sostenible
}

\section{Resumen}

El presente artículo intenta reabrir el debate de vieja data en el campo del derecho internacional del comercio, respecto de la norma aplicable al caso de las medidas relativas a los métodos y procesos de producción que conllevan una prohibición a la importación de bienes. Cierta jurisprudencia relativa al Acuerdo General sobre Aranceles Aduaneros y Comercio (GATT, por sus siglas en inglés) de 1947 se inclinó a favor de la aplicación del artículo XI de este acuerdo, referido a las restricciones cuantitativas al comercio, en desmedro del artículo III que consagra el principio de tratamiento nacional. Este ensayo pretende demostrar que, en el marco del GATT de 1994, la disyuntiva planteada debe ser resuelta a favor de la aplicación del artículo III, habida cuenta de la presencia de un nuevo contexto normativo que obliga al intérprete a tomar en consideración el principio de desarrollo sostenible en el momento de analizar dicho acuerdo.

Palabras clave: Acuerdo General sobre Aranceles Aduaneros y Comercio (GATT), desarrollo sostenible, discriminación comercial, métodos y procesos de producción, Organización Mundial del Comercio (oмc).

\section{The principle of sustainable development and its influence on the interpretation of GATT Article III at the moment of the evaluation of the legality of trade restrictive measures based on processes and production methods}

\begin{abstract}
This article attempts to reopen the debate, of long standing in the field of international trade law, respect of the rule applicable to the case of trade measures relating to process and production methods that involve a ban on the import of goods. Some jurisprudence under GATT 1947 is tilted in favor of the application of Article XI of this Agreement concerning quantitative restrictions on trade, to the detriment of Article III, which enshrines the principle of national treatment. This essay attempts to show that, under the GATT 1994, the dilemma raised must be resolved in favor of the application of Article III, given the presence of a new regulatory context, which requires the interpreter to take into account the principle of sustainable development when analysing the agreement.

Key words: General Agreement on Tariffs and Trade (GATT), process and production methods, sustainable development, trade discrimination, World Trade Organization (WTO).

\section{O artigo III do GATT: norma aplicável para as medidas comerciais restritivas relativas aos métodos e processos de produção em virtude do princípio de desenvolvimento sustentável}

\section{Resumo}

O presente artigo tenta reabrir o debate de longa data no campo do direito internacional do comércio, com respeito à norma aplicável ao caso das medidas relativas aos métodos e processos de produção que implicam uma proibição da importação de bens. Certa jurisprudência relativa ao Acordo Geral sobre Pautas Aduaneiras e Comércio (GATT, por suas siglas em inglês) de 1947 se inclinou a favor da aplicação do artigo XI deste acordo, referido as restrições quantitativas ao comércio, em desmedro do artículo III que consagra o princípio de tratamento nacional. Este ensaio pretende demostrar que, no marco do GATT de 1994, a disjuntiva apresentada deve ser resolvida a favor da aplicação do artigo III, tendo em conta a presença de um novo contexto normativo que obriga o intérprete a levar em consideração o princípio de desenvolvimento sustentável no momento de analisar dito acordo.
\end{abstract}

Palavras-chave: Acordo Geral sobre Pautas Aduaneiras e Comércio (GATT), desenvolvimento sustentável, discriminação comercial, métodos e processos de produção, Organização Mundial do Comercio (OMC). 
Sumario

Introducción - I. EL ARTÍCULO III VERSUS EL ARTÍCULO XI DEL GATT: BREVE RECUENTO DE LOS CRITERIOS JURISPRUDENCIALES APLICADOS EN LOS CASOS ATÚN-DELFÍN - A. Los artículos III y XI del GATT - B. Los informes emitidos en los casos Atún-Delfín I y II - II. ANÁLISIS CRÍTICO DE LAS DECISIONES ATÚN-DELFÍN - A. Debilidades de las decisiones Atún-Delfín en el marco del GatT de 1947 - B. Las decisiones Atún-Delfín I y ll a la luz del principio de desarrollo sostenible en el marco del GatT de 1994 - III. CONCLUSIONES - Bibliografía. 


\title{
El artículo III del GATT: norma aplicable a las medidas comerciales restrictivas relativas a los métodos y procesos de producción en virtud del principio de desarrollo sostenible ${ }^{1}$
}

\author{
Francisco Villanueva ${ }^{2}$
}

Introducción

El presente artículo se centra, fundamentalmente, en la exégesis de normas y jurisprudencia de derecho internacional del comercio. Tal ejercicio responde, sin embargo, a inquietudes surgidas en el marco más amplio del debate relativo al vínculo entre el régimen jurídico de la Organización Mundial del Comercio (omc) ${ }^{3}$ y otras ramas del derecho internacional, tales como el derecho

1 Cómo citar este artículo: Villanueva, F. (Junio, 2014). El artículo III del GATT: norma aplicable a las medidas comerciales restrictivas relativas a los métodos y procesos de producción en virtud del proceso de desarrollo sostenible. Revista de Derecho Público, 32.

2 Miembro del Colegio de Abogados de Lima. Doctor en Derecho (LL. D., Université de Montréal). Magíster en Derecho Internacional EconómiCo (D. E. A., Université Panthéon-Sorbonne) y en Relaciones Industriales (M. A., Université Laval). Profesor regular permanente (Associate Professor) de la École des sciences de la gestion de la Université du Québec à Montréal (UQȦM) en el área de Relaciones Industriales. Correo: villanueva.francisco@uqam.ca

3 Creada en 1994 en virtud del Acuerdo de Marrakech (15 de abril de 1994), la omc inició sus actividades el $1^{\circ}$ de enero de 1995 . Esta organización rectora del comercio internacional de bienes y servicios constituye el marco institucional en el seno del cual se desarrollan las relaciones entre los Estados miembros, regidas por 18 acuerdos y otros instrumentos complementarios, entre los cuales se encuentra el Acuerdo General sobre Aranceles Aduaneros y Comercio (GATT, por sus siglas en inglés). internacional del trabajo o el derecho internacional del medio ambiente. Dicho debate engloba la cuestión de la tolerancia del derecho internacional del comercio respecto de medidas de carácter social o ambiental. Conforme veremos más adelante, aunque el punto de partida de nuestras investigaciones concierne al estudio del vínculo entre las normas comerciales y las normas laborales a nivel internacional, resulta imprescindible analizar la jurisprudencia comercial ligada a cuestiones de carácter ambiental, en la medida que esto permite inferir principios susceptibles de ser extrapolados a situaciones de naturaleza social. Tal necesidad nace, principalmente, de la carencia de jurisprudencia específica relacionada con el vínculo entre las normas laborales y las normas comerciales.

Para una mejor comprensión del contexto en el cual surgen los cuestionamientos sobre la permeabilidad del derecho internacional del comercio, respecto de medidas destinadas a garantizar el respeto de normas de naturaleza laboral, es menester recordar que en el marco del pro- 
ceso de liberalización progresiva del comercio mundial se ha discutido por buen tiempo, y con una cierta dosis de apasionamiento, la inclusión de mecanismos de condicionalidad social al interior del sistema jurídico de la omc. Se trata de una cuestión que no es ciertamente reciente, pues sus orígenes se remontan a la fallida creación de la Organización Internacional del Comercio, en 1948. Algunos la vinculan incluso a la aparición en la escena internacional de la Organización Internacional del Trabajo (отт)4. Es, sin embargo, en el transcurso de los años 1990 que el tema cobró protagonismo, cuando los sindicatos que representaban los intereses de los trabajadores de los países desarrollados hicieron sentir su voz de manera airada denunciando la invasión de sus mercados nacionales por productos fabricados con mano de obra barata (cheap labour) en el Tercer Mundo. Se debe reconocer, sin embargo, que algunos Estados adoptaron como estrategia para atraer inversiones internacionales, el desarrollo de ventajas comparativas sobre la base de una extrema flexibilización de sus legislaciones laborales, por no decir, en algunos casos, de la explotación despiadada de la mano de obra. Buen ejemplo de ello son algunas "zonas francas" o "maquiladoras", en las que suelen ser frecuentes prácti-

4 En el preámbulo de la Constitución de la oIt se señala que "si cualquier nación no adoptare un régimen de trabajo realmente humano, esta omisión constituiría un obstáculo a los esfuerzos de otras naciones que deseen mejorar la suerte de los trabajadores en sus propios países". Esto constituye una clara alusión a la necesidad de garantizar un nivel mínimo de protección social a nivel internacional, con el objeto de penalizar comercialmente a aquellos países que vieran aumentar sus costos de protección como consecuencia del desarrollo de su legislación laboral. cas de naturaleza antisindical o discriminatoria en detrimento del personal femenino ${ }^{5}$.

Con el objeto de limitar los efectos del fenómeno mencionado en el párrafo anterior, calificado de manera impropia como dumping social, surgieron diversas propuestas tendientes a implantar una cláusula social en el marco normativo de la омc, es decir, de una regla que condicionara el goce continuo de las concesiones arancelarias obtenidas en virtud del GATT con respeto a las normas laborales. Sin embargo, pese a que tal posibilidad quedó completamente excluida en el transcurso de los años 1990 a raíz de la firme oposición de los países en vías de desarrollo, cierto sector de la doctrina continúa preguntándose si, en su estado actual, el derecho de la omc podría admitir la introducción de una condicionalidad social, por la vía de la interpretación de sus normas. Esto implicaría aceptar como lícitas medidas coercitivas de naturaleza comercial, destinadas a asegurar el respeto de normas pertenecientes al derecho internacional del trabajo o al derecho internacional de los derechos humanos ${ }^{6}$. Como es sabido, la oIT ha sido acusada en múltiples ocasiones de ser una institución que carece de poderes sancio-

5 A título de ejemplo cabe mencionar los análisis exigidos a trabajadoras con el objeto de marginar a aquellas que estén embarazadas.

6 Sobre esta cuestión ver, por ejemplo: Blackett (1999, pp. 2-80), Cleveland (2001, pp. 199-261), Denkers (2008), Di Turi (2007), Hepple (2005), Francioni (2006, pp. 143-154) y Giansanti (2008).

7 La Organización Internacional del Trabajo fue creada en 1919 en el marco del Tratado de Versalles que puso fin a la Primera Guerra Mundial. Tiene como principales objetivos fomentar la cooperación técnica a nivel internacional en el campo laboral y adoptar normas internacionales del trabajo, principalmente, bajo la forma de convenciones y recomendaciones. 
nadores suficientes que le permitan imponer el respeto a nivel internacional de tales derechos ${ }^{8}$. Esta percepción ha tenido como efecto que distintos autores se pregunten si la prohibición de importación de productos fabricados transgrediendo los derechos de los trabajadores podría erigirse como un método eficaz para asegurar el respeto de estos últimos.

Dicho esto, quienes participan en el debate sobre la llamada condicionalidad social del comercio no pueden dejar de interrogarse sobre la licitud de las medidas restrictivas de naturaleza comercial dirigidas a garantizar el pleno respeto de los derechos fundamentales de los trabajadores, en el marco de los procesos de producción. Se trata de una cuestión que genera numerosas interrogantes, particularmente, desde el punto de vista del derecho de la omc, el cual constituye, a nuestro entender, el principal escollo jurídico para su adopción. Así, cabe preguntarse si, de conformidad con el régimen general del GATT, es lícito, por ejemplo, que un país miembro de dicha organización impida la importación de mercaderías fabricadas por niños expuestos a condiciones de trabajo que ponen en peligro su salud física o mental, dado que en su territorio existe una prohibición que afecta la comerciali-

8 Por ejemplo, Mehmet, Mendes y Sinding (1999, p. 10) califican irónicamente a la oit de "dog with a soft bark and not much of a bite". Se trata de una acusación que podría parecer fundada si nos atenemos a la práctica de esta organización, pero que no guarda armonía con el potencial coercitivo que encierra el artículo 33 de la Constitución de la oit, el cual prevé que dentro del marco del procedimiento de Queja "el Consejo de Administración recomendará a la Conferencia las medidas que estime convenientes para obtener el cumplimiento" de las recomendaciones formuladas por la comisión de encuesta al país al que se le imputa el no respeto de una convención internacional del trabajo. La oit ha aplicado esta disposición solamente una vez en su historia para hacer frente a situaciones de trabajo forzoso en Birmania. zación de todo producto, nacional o importado, fabricado en tales condiciones ${ }^{9}$. ¿Pueden considerarse legítimas las medidas restrictivas adoptadas sobre la base de la manera como el bien ha sido producido, aun cuando el proceso de fabricación no tenga ninguna influencia en las características y cualidades del producto? Cabe recordar que este tipo de medidas es conocido, en el ámbito del derecho internacional del comercio, bajo el nombre de "medidas relativas a los procesos y los métodos de producción" (en adelante MRPMP). Como su nombre lo indica, las MRPMP no buscan influir en las características físicas de los productos (aunque en algunos casos sí pueden tener un impacto sobre estas), sino en el modo como estos son fabricados ${ }^{10}$.

Ahora bien, para evaluar la licitud de las MRPMP que adoptan la forma de una prohibición a la importación de bienes es preciso definir, antes que nada, cuál es la norma del régimen general Ilamada a zanjar esta cuestión. ¿Es el artículo III del GATT que consagra el principio de tratamiento nacional? ¿O es más bien su artículo XI, el cual prohíbe las restricciones cuantitativas al comercio? La respuesta a las preguntas planteadas implica establecer si las medidas que nos ocupan pueden ser ubicadas dentro de la categoría

9 Tales medidas podrían ser adoptadas, por ejemplo, en cumplimiento de la Convención de la oIt n. ${ }^{\circ} 182$, en virtud de la cual "todo Miembro deberá adoptar cuantas medidas sean necesarias para garantizar la aplicación y el cumplimiento efectivos de las disposiciones por las que se dé efecto al presente Convenio, incluidos el establecimiento y la aplicación de sanciones penales o, según proceda, de otra índole" (artículo 7).

10 Recordemos que, desde una perspectiva jurídica-comercial, las MRPMP pueden ser vistas de dos maneras alternativas: i) como medidas internas vinculadas al logro de objetivos no comerciales o ii) como restricciones cuantitativas al comercio exterior, de carácter proteccionista. 
de medidas internas o si, por el contrario, constituyen meras restricciones cuantitativas al comercio. En el primer caso, el artículo III sería la norma llamada a evaluar su conformidad con el régimen general del GATT y, por lo mismo, el análisis debería centrarse en el eventual carácter discriminatorio de las medidas. Por el contrario, si se negase a las medidas adoptadas para restringir la importación de productos fabricados transgrediendo los derechos de los trabajadores el carácter de medidas internas, incluyéndolas en la categoría de restricciones cuantitativas, se debería dar paso a la aplicación del artículo XI del GATT (Pauwelyn, 2005). Cabe recordar que se trata de una disyuntiva que va más allá de un mero ejercicio teórico, conforme veremos más adelante, y que fue abordada por los grupos especiales Ilamados a resolver los diferendos conocidos como "Atún-Delfín" | ${ }^{11}$ y II ${ }^{12}$, antes de la creación de la omc en 1994, los cuales se pronunciaron a favor de la aplicación del artículo XI. Esta toma de posición implicaba considerar de plano las prohibiciones de importación vinculadas a los procesos y métodos de producción de bienes (PMP) como contrarias al régimen general del GatT. Si bien fueron decisiones emitidas en casos que concernían a cuestiones ambientales, sus repercusiones en el campo laboral son enormes, como demostraremos más adelante, dado que los criterios utilizados entrañan que toda prohibición de importación que afecte a productos fabricados en violación de los derechos de los trabajadores deba ser considerada

11 Conocido también bajo el nombre de EE. UU.-Atún I.

12 Conocido también bajo el nombre de EE. UU.-Atún II. como ilícita, desde el punto de vista del régimen general del GATT. La ilicitud de tal tipo de prohibición significaría que las medidas solo podrían ser justificadas invocando las excepciones del artículo XX del mismo acuerdo, siempre y cuando se respeten las rigurosísimas condiciones que este impone ${ }^{13}$.

En el presente artículo defenderemos la tesis según la cual el asunto debe ser objeto de un nuevo análisis, a la luz del marco normativo e institucional al que el GaTT fue incorporado a partir del $1^{\circ}$ de enero de $1995^{14}$. Sobre la base de esta premisa, demostraremos que el artículo del III GATT es la norma del régimen general Ilamada a zanjar la cuestión de la licitud de las prohibiciones a la importación basadas en los PMP. En efecto, si analizamos los cimientos jurídicos sobre los cuales reposa actualmente el entramado de tratados que los Estados miembros de dicha institución se han comprometido a respetar, entre los que se encuentra el GATT,

13 El artículo $\mathrm{XX}$ del GATT permite a los Estados miembros de la OMC sustraerse de las obligaciones consagradas en el régimen general de este acuerdo y adoptar medidas que buscan la protección de intereses y valores de distinta naturaleza, no necesariamente de carácter económico, como por ejemplo, la vida y la salud de las personas, la moral pública, los recursos naturales no renovables, etc. Las medidas restrictivas del comercio adoptadas al amparo del artículo XX del GATT están sujetas a un examen en dos fases. En un primer momento se analiza si la medida está incluida en el ámbito de aplicación de una de las diez excepciones del artículo XX (a-j). Con tal objetivo, se debe comprobar si los requisitos inherentes a cada una de esas excepciones son respetados. En segundo lugar, el análisis concierne el preámbulo del artículo XX. En esta fase se debe verificar, primeramente, que las medidas no sean aplicadas de tal modo que puedan constituir un mecanismo de discriminación arbitrario o injustificado entre Estados en los que existen las mismas condiciones. Ulteriormente, debe comprobarse que las medidas no acarreen una restricción encubierta del comercio internacional.

El GATT es un acuerdo concluido en 1947 que precede a la existencia de la omc. A partir de la creación de la omc, se distingue entre el GATT de 1947 y el GATT de 1994, que retoma el acuerdo primigenio con algunas modificaciones. 
emerge como norma fundamental el Acuerdo de Marrakech, que se encuentra en el origen mismo de la omc y que fue adoptado con posterioridad a las decisiones Atún-Delfín I y III5.

En el preámbulo del Acuerdo de Marrakech las partes consagran el principio de desarrollo sostenible, el cual está llamado a jugar un rol de primer orden en el momento de interpretar el texto del GATT, conforme lo explicaremos en las páginas que siguen. Nuestro estudio tiene como objetivo demostrar la manera como dicho principio, el cual forma parte del contexto interno vigente a la luz del cual el GatT tiene que ser interpretado actualmente, debería guiar el razonamiento del Órgano de Solución de Diferendos de la omc (OSD) cuando sea llamado a resolver un diferendo que verse sobre restricciones a la importación relativas a los PMP y tenga que pronunciarse sobre la aplicación de los artículos III y XI de dicho acuerdo. La consideración del principio de desarrollo sostenible en el proceso hermenéutico debería necesariamente, desde nuestro punto de vista, llevar a conclusiones distintas a las que llegaron los paneles en los casos Atún-Delfín I y II.

En la primera parte de este artículo haremos una síntesis de las decisiones recaídas en los casos Atún-Delfín I y II (I). En la segunda parte efectuaremos un análisis crítico de las decisio-

15 Desde un punto de vista normativo, el sistema de la omc incluye, además del Acuerdo de Marrakech, 18 acuerdos (acuerdos anexos) y otros instrumentos adicionales. Desde el punto de vista jerárquico, el Acuerdo de Marrakech se encuentra en el vértice del sistema. Tres acuerdos anexos erga omnes partes, cuyo respeto se impone a todos los miembros de la омc, son piezas importantes del sistema: el Acuerdo General sobre Aranceles Aduaneros y Comercio (GATT), el Acuerdo General sobre el Comercio de Servicios (AGCS) y el Acuerdo sobre los Aspectos de los Derechos de Propiedad Intelectual relacionados con el Comercio (ADPIC). nes antes mencionadas, y demostraremos que la aplicación del principio de desarrollo sostenible debería llevarnos a descartar la aplicación del artículo XI del GatT al caso de las MRPMP que adoptan la forma de una prohibición a la importación de bienes y a privilegiar la aplicación del artículo III de dicho acuerdo (II).

\section{EL ARTÍCULO III VERSUS EL ARTÍCULO XI DEL GATT: BREVE RECUENTO DE LOS CRITERIOS JURISPRUDENCIALES APLICADOS EN LOS CASOS ATÚN-DELFÍN I Y II}

En esta sección presentaremos de manera sintética el contenido de los artículos III y XI del GATT y la función que cumplen en el marco de este acuerdo (A). En segundo lugar, haremos una breve sinopsis de los informes de los grupos especiales relativos a los casos Atún-Delfín I y II (B).

\section{A. Los artículos III y XI del GATT}

El artículo III del GATT consagra el principio de tratamiento nacional. Para una mejor comprensión del rol que estaría llamado a cumplir en el caso de restricciones a la importación vinculadas a Ios PMP, es pertinente tomar en cuenta los siguientes párrafos de esta norma:

Trato nacional en materia de tributación y de reglamentación interiores

1. Las partes contratantes reconocen que los impuestos y otras cargas interiores, así como las leyes, reglamentos y prescripciones que afecten a la venta, la oferta para la venta, la 
compra, el transporte, la distribución o el uso de productos en el mercado interior y las reglamentaciones cuantitativas interiores que prescriban la mezcla, la transformación o el uso de ciertos productos en cantidades o en proporciones determinadas, no deberían aplicarse a los productos importados o nacionales de manera que se proteja la producción nacional.

2. Los productos del territorio de toda parte contratante importados en el de cualquier otra parte contratante no estarán sujetos, directa ni indirectamente, a impuestos interiores $u$ otras cargas interiores, de cualquier clase que sean, superiores a los aplicados, directa o indirectamente, a los productos nacionales similares. Además, ninguna parte contratante aplicará, de cualquier otro modo, impuestos u otras cargas interiores a los productos importados o nacionales, en forma contraria a los principios enunciados en el párrafo 1.

4. Los productos del territorio de toda parte contratante importados en el territorio de cualquier otra parte contratante no deberán recibir un trato menos favorable que el concedido a los productos similares de origen nacional, en lo concerniente a cualquier ley, reglamento o prescripción que afecte a la venta, la oferta para la venta, la compra, el transporte, la distribución y el uso de estos productos en el mercado interior. Las disposiciones de este párrafo no impedirán la aplicación de tarifas diferentes en los transportes interiores, basadas exclusivamente en la utilización económica de los medios de transporte y no en el origen del producto.

El citado artículo obliga a los Estados miembros a acordar a los productos importados, provenientes de otro Estado miembro, un tratamiento que no sea menos favorable respecto del otorgado a los productos nacionales similares, tanto desde el punto de vista tributario como desde el punto de vista de las medidas internas. Bhala (2005, p. 95) sintetiza de manera muy elocuente el objetivo perseguido por el artículo III del GATT: "[n]ational treatment calls for loving one's neighbour like oneself". En efecto, el artículo en cuestión fue concebido con miras a garantizar que los productos importados puedan competir en el mercado local en las mismas condiciones que los productos nacionales. Por tal motivo, tal como lo recuerda Luff (2004), el artículo III del GATT prohíbe toda medida proteccionista del Estado importador a favor de los productos nacionales y lo obliga a abstenerse de adoptar cualquier medida que entrabe o impida la comercialización de los productos importados. Cabe resaltar, además, que en virtud del artículo III del GATT, cualquier medida de carácter interno que tenga por objeto proteger el mercado nacional debe ser objeto de negociación y adoptar la forma de un arancel (Mavroidis, 2007). Los conceptos vertidos precedentemente son compartidos por la jurisprudencia del OSD. Así por ejemplo, en el marco del diferendo "Japón-Impuesto sobre las bebidas alcohólicas", el Órgano de Apelación de la omc tuvo la ocasión para recordar que:

El objetivo general y fundamental del artículo III es evitar el proteccionismo en la aplicación de los impuestos y medidas reglamentarias interiores. Más concretamente, el propósito del artículo III "es el de que las medidas interiores no se apliquen a los productos importados o nacionales de manera que se proteja la producción nacional". A este fin, el artículo III 
obliga a los Miembros de la omc a facilitar para los productos importados unas condiciones de competencia iguales a las de los productos nacionales. "[L]os redactores del Acuerdo General tuvieron manifiestamente la intención de que los productos importados, después de abonados los derechos de aduana correspondientes, sean tratados de la misma manera que los productos similares de origen nacional; de ser de otro modo se podría conceder una protección indirecta" (sección F, p. 20) ${ }^{16}$.

Cabe añadir que el Órgano de Apelación ha dejado también sentado que el objetivo antiproteccionista del artículo III se encuentra contemplado en su primer párrafo, el cual debe orientar la interpretación de los párrafos 2 y $4^{17}$.

Por otro lado, en virtud del primer párrafo de la Disposición Suplementaria del artículo III del Anexo I del GATT:

Todo impuesto interior u otra carga interior, o toda ley, reglamento o prescripción de la clase a que se refiere el párrafo 1 , que se aplique al producto importado y al producto nacional similar y que haya de ser percibido o impuesto, en el caso del producto importado, en el momento o en el lugar de la importación, será, sin embargo, considerado como un impuesto interior u otra carga interior, o como una ley, reglamento o prescripción de la clase mencionada en el párrafo 1, y estará, por consiguiente, sujeto a las disposiciones del artículo III.

16 Las notas bibliográficas del original han sido suprimidas.

17 Se trata de la decisión recaída en el caso CE-Amianto (2001)
En consecuencia, el campo de aplicación del artículo III abarca las medidas que atañen tanto a los productos importados como a los productos nacionales, y cuya aplicación efectiva, en el caso de los productos importados, tiene efecto en la frontera (Mavroidis, 2007). Tal sería el caso, por ejemplo, de una prohibición general que impida el comercio de bienes fabricados por personas que se encuentran en situación de esclavitud, donde poco importa si los productos en cuestión han sido elaborados al interior o al exterior del país que adopta tal medida. Asimismo, debemos subrayar que el artículo III del GaTT no se limita únicamente a la discriminación jurídica, sino que comprende también la discriminación fáctica. Por ello, la aplicación del artículo III es procedente no solo en el caso de las medidas susceptibles de ser consideradas discriminatorias en razón de una distinción que encuentra fundamento en el origen del producto, sino también en aquellos supuestos en los que las medidas son aparentemente neutras desde el punto de vista de la procedencia del producto pero que, sin embargo, tienen efectos discriminatorios (Van den Bossche, Schrijver y Faber, 2007).

Por su parte, el artículo XI del GATT consagra el principio de la protección arancelaria exclusiva. Este principio obliga a los Estados miembros a erradicar todas las barreras comerciales que no poseen naturaleza arancelaria (López Jurado y Martín, 2010). Según el primer párrafo del artículo XI:

Ninguna parte contratante impondrá ni mantendrá -aparte de los derechos de aduana, impuestos $u$ otras cargas- prohibiciones ni 
restricciones a la importación de un producto del territorio de otra parte contratante o a la exportación o a la venta para la exportación de un producto destinado al territorio de otra parte contratante, ya sean aplicadas mediante contingentes, licencias de importación o de exportación, o por medio de otras medidas.

La precitada regla ha sido concebida con el fin de afianzar la estabilidad y el buen funcionamiento del GATT frente a la amenaza que representan las medidas proteccionistas que no se manifiestan a través de un arancel. Debemos convenir con Jackson (1997) que el compromiso asumido por los Estados miembros, consistente en reducir de manera progresiva los aranceles, podría ser fácilmente eludido si no fuese por la presencia del artículo XI en el texto del mencionado acuerdo. Asimismo, cabe resaltar, retomando las ideas de Guzmán y Pauwelyn (2009), que el vasto enunciado del artículo XI responde al reto planteado por la gran variedad de estratagemas de carácter proteccionista que pueden ser concebidas con miras a debilitar la posición competitiva de los productos importados.

A fin de comprender la importancia que reviste el artículo XI del GaTT y las razones por las que es invocado a menudo en el marco de los diferendos que enfrentan a los Estados miembros de la omc, consideramos pertinente traer a colación las reflexiones de Picone y Ligustro (2002) en el sentido de que los efectos negativos de las medidas no-arancelarias sobre el comercio pueden resultar más insidiosos que los aranceles. En primer lugar, dichas medidas corroen solapadamente el sistema de liberalización progresiva del comercio de la omc. En segundo lugar, las medidas no-arancelarias tienen efectos nefastos sobre el mercado, puesto que restringen arbitrariamente tanto las actividades de los productores como la capacidad de elegir de los consumidores. No debe sorprendernos, por consiguiente, que muchos Estados miembros hayan intentado contestar la licitud de medidas referidas a los PMP valiéndose del artículo XI del GATT.

La identificación de los efectos proteccionistas o anticompetitivos de una medida comercial restrictiva, desde el punto de vista del artículo XI del GATT, es prácticamente automática cuando la medida en cuestión comprende únicamente los productos importados y excluye los nacionales (Picone y Ligustro, 2002). Sin embargo, la aplicación del artículo XI presenta mayor complejidad y suscita polémica cuando las medidas adoptadas en el proceso de ejecución de una ley son aplicables a los PMP de los productos tanto importados como nacionales, pero los efectos restrictivos de tales medidas se limitan a los productos importados, debido a que los productos nacionales son fabricados de conformidad con dicha ley. Tal sería el caso, por ejemplo, de una medida que prohíba la comercialización en un país desarrollado, como por ejemplo Canadá, de productos fabricados por personas que se encuentran en situación de servidumbre por deudas, una situación que desafortunadamente no es rara en algunos países de Asia, como la India. Puesto que todos los productores canadienses fabrican bienes sin recurrir al empleo de ese tipo de mano de obra, la prohibición en cuestión afectaría únicamente los productos importados en Canadá provenientes de la India. 


\section{B. Los informes emitidos en los casos Atún-Delfín I y II}

El análisis de los informes emitidos por los grupos especiales de los diferendos Atún-Delfín I y II resulta fundamental, habida cuenta que estos son los únicos casos en los que la jurisprudencia relativa al GATT aborda de manera explícita la disyuntiva entre la aplicación de los artículos III u XI del GaTT -más precisamente, los artículos III:4 u XI:1- a las prohibiciones de importación relativas a los PMP (Fernández, 2008). No se puede, sin embargo, soslayar el hecho de que en el caso Camarones-Tortugas ${ }^{18}$, diferendo suscitado a raíz de la aplicación de un sistema de certificación estadounidense que tenía por objeto preservar la sobrevivencia de las tortugas marinas como especie, el Grupo Especial concluyó que la medida americana era contraria al artículo XI del GATT. Sin embargo, esta controversia no puso punto final a la polémica planteada respecto de la aplicación del artículo III, habida cuenta que Estados Unidos basó su defensa en las excepciones del artículo XX del GATt. Dicho esto, antes de presentar de manera sintética los informes de los paneles de los casos AtúnDelfín, se imponen dos precisiones importantes. En primer lugar, cabe recordar que estas fueron adoptadas en 1991 y 1994, respectivamente, es decir, antes de que la omc entrara en funciones. En segundo lugar, su valor jurisprudencial debe ser relativizado, puesto que nunca fueron

Conocido también bajo el nombre de EE. UU.-Camarones. adoptadas oficialmente por el Consejo de representantes del GATT ${ }^{19}$.

La controversia surgida entre México y Estados Unidos en el caso Atún-Delfín I encuentra su origen en la adopción, por parte de este último país, de la Marine Mammal Protection Act (MMPA). Esta ley autorizaba la adopción de medidas comerciales restrictivas a fin de impedir la importación de atún que hubiera sido pescado poniendo en peligro la vida de delfines ${ }^{20}$. En la práctica, dichas medidas causaban perjuicio a las exportaciones mexicanas de atún hacia Estados Unidos. Para este último, el diferendo debía circunscribirse a la aplicación del artículo III:4 del GatT. Según la posición americana, la restricción relativa a la importación de atún atrapado utilizando métodos de pesca considerados como dañinos para los delfines supone la aplicación de medidas internas a un producto en el momento de la importación, supuesto de hecho previsto en el artículo III:4 del Gart. A fin de sustentar su posición, Estados Unidos invocó el primer párrafo de la Disposición Suplementaria del artículo III del GatT, según el cual, este artículo está llamado a intervenir cuando una prescripción interna concierne tanto los productos nacionales como los productos importados,

19 En el sistema de resolución de controversias del GATT de 1947, previo a la omc, bastaba que un país miembro votara contra la adopción del informe del Grupo Especial para que esta fuera bloqueada. Generalmente, la actitud obstruccionista provenía, evidentemente, del país al cual el Grupo Especial no había dado la razón.

20 En algunas zonas tropicales del Pacífico los bancos de atún son acompañados por delfines, los cuales quedan accidentalmente atrapados en las redes de los barcos pesqueros. El gobierno de Estados Unidos previó que solo fuera posible importar atún proveniente de países con un sistema de control comparable al implementado por Estados Unidos y con cuotas de muerte accidental de delfines semejantes a las americanas. 
inclusive si la medida es aplicada en el punto de importación.

Retomando las ideas de Pauwelyn (2003), cabe indicar que el mero hecho de que el respeto de determinadas normas comerciales sea asegurado en el punto de importación ${ }^{21}$ no convierte a las medidas de ejecución de tales normas en restricciones cuantitativas al comercio, sujetas al artículo XI del GATT. Si se asumiera lo contrario, cualquier medida interna adoptada por el país importador que también resultara aplicable a los productos importados de los otros países miembros debería ser considerada ilícita, en virtud del artículo XI, por el simple hecho de restringir la importación de mercancías. Resulta lógico, entonces, que Estados Unidos enfatizara que las medidas adoptadas en aplicación de la MMPA poseían el carácter de prescripción interna, a efectos de evitar que sean consideradas como simples restricciones cuantitativas comprendidas en el ámbito de aplicación del artículo XI del GATT.

En lo que se refiere a la posición mexicana en el diferendo Atún-Delfín I, esta rechazaba de plano la aplicación del artículo III:4 del Gatr. Según México, las medidas americanas vinculadas a la MMPA no eran otra cosa que restricciones cuantitativas al comercio regidas por el artículo XI de dicho acuerdo. El enfoque mexicano no se inscribe en el marco de un ejercicio meramente teórico. En efecto, la aplicación del artículo III conlleva consecuencias más onerosas para el

21 La verificación en el momento en que se produce la importación puede presentarse como la opción más eficaz para la autoridad nacional. país denunciante que las que fluyen del artículo XI. Así, en virtud del artículo III, el Estado exportador que alega una violación al principio de tratamiento nacional, no solo tendrá que demostrar la existencia de restricciones comerciales que afectan la entrada de determinados productos al territorio del Estado importador, responsable de dichas medidas, sino también que los productos en cuestión son similares a productos nacionales de este Estado, y que los primeros son objeto de un tratamiento menos favorable respecto de estos últimos (Mavroidis, 2007).

En el marco del diferendo Atún-Delfín I, el Grupo Especial decidió acoger la posición mexicana sobre la base de una interpretación restrictiva del artículo III, centrada en el empleo del término "productos" en su texto. Así, asumió que la MMPA no regulaba el atún como producto, así como tampoco métodos de producción que pudieran tener un impacto tangible sobre dicha mercancía, y dejó sentado que las medidas relativas a los PMP, que no determinan ni la comercialización ni la naturaleza de un producto, se encuentran fuera del ámbito de aplicación del artículo III del GATT, especialmente del artículo III:4 y de la Disposición Suplementaria del artículo III del GaTT ${ }^{22}$. Como Howse y Regan (2008)

22 Según el informe del Grupo Especial, "[t]he MMPA did not regulate tuna products as such, and in particular did not regulate the sale of tuna or tuna products. Nor did it prescribe fishing techniques that could have an effect on tuna as a product" (párrafo 5.10). Adicionalmente, indicó que: "[t]he text of Article III:1 refers to the application to imported or domestic products of "laws, regulations and requirements affecting the internal sale.... of products" and "internal quantitative regulations requiring the mixture, processing or use of products"; it sets forth the principle that such regulations on products not be applied so as to afford protection to domestic production. Article III:4 refers solely to laws, regulations and requirements affecting the internal sale, etc. of products. This suggests that Article III covers only measures affecting products 
lo señalan, el Grupo Especial tenía la convicción de que las disposiciones antes citadas debían ser entendidas en el sentido de que los aspectos relevantes, a efectos de la aplicación de las consecuencias jurídicas en ellas previstas, son los productos en sí mismos y su naturaleza, un término asociado por el Grupo Especial a las características físicas del producto. Según el razonamiento empleado por el Grupo Especial, la MMPA hubiera sido relevante a efectos de la aplicación del artículo III del GaTT si las medidas de ejecución de esta ley hubieran ejercido una influencia en las características del atún, en tanto que producto.

A mayor abundamiento, conforme Fernández (2008) lo pone de relieve, para justificar la no aplicación del artículo III del GATT el Grupo Especial del caso Atún-Delfín I tuvo en cuenta también las conclusiones del Grupo de Trabajo en el asunto Ajustes Fiscales en Fronteras de 1970, en las cuales se señala que los tributos que no incidan directamente sobre los productos no debían ser considerados en el ajuste fis$\mathrm{cal}^{23}$. Tal es el caso, por ejemplo, de los tributos vinculados a la seguridad social o a las remuneraciones pagadas por los empleadores a su

as such. Furthermore, the text of the Note Ad Article III refers to a measure "which applies to an imported product and the like domestic product and is collected or enforced in the case of the imported product at the time or point of importation". This suggests that this Note covers only measures applied to imported products that are of the same nature as those applied to the domestic products, such as a prohibition on importation of a product which enforces at the border an internal sales prohibition applied to both imported and like domestic products" (párrafo 5.11).

23 El ajuste fiscal a la frontera permite evitar la doble imposición. Implica un desgravamen concedido al producto al salir de un territorio aduanero y un gravamen en el punto de entrada a otro territorio, el cual lo coloca en situación de igualdad en relación con los productos nacionales. personal. Según el Grupo Especial del diferendo Atún-Delfín I, sería incongruente con las mencionadas conclusiones excluir del ámbito de aplicación del artículo III del GatT a los tributos que no gravan directamente los productos objeto de comercio y, al mismo tiempo, admitir la incorporación en dicho ámbito de medidas que no tienen impacto directo en el producto, como son los métodos de pesca del atún que buscan evitar la muerte de delfines ${ }^{24}$.

En resumidas cuentas, el Grupo Especial del caso Atún-Delfín I concluyó que es el artículo XI:1 del GATT, y no el artículo III, la norma llamada a zanjar la cuestión de la licitud de las medidas americanas vinculadas a la MMPA, por tratarse, en su opinión, de restricciones cuantitativas al comercio. Según el Grupo Especial, la aplicación del artículo III y de su Disposición Suplementaria debería estar limitada a aquellas situaciones en las que los PMP son susceptibles de tener un impacto en las características físicas del producto (Musselli, 2001; Fernández, 2008). Los criterios antes mencionados fueron retomados por el Grupo Especial del caso Atún-Delfín II, cuyos elementos fácticos eran similares a los del pre-

24 De acuerdo con el Grupo Especial, "[t]he Panel considered that, as Article III applied the national treatment principle to both regulations and internal taxes, the provisions of Article III:4 applicable to regulations should be interpreted taking into account interpretations by the CONTRACTING PARTIES of the provisions of Article III:2 applicable to taxes. [...] Thus, under the national treatment principle of Article III, contracting parties may apply border tax adjustments with regard to those taxes that are borne by products, but not for domestic taxes not directly levied on products (such as corporate income taxes). Consequently, the Note Ad Article III covers only internal taxes that are borne by products. The Panel considered that it would be inconsistent to limit the application of this Note to taxes that are borne by products while permitting its application to regulations not applied to the product as such" (párrafo 5.13). Se trata, evidentemente, de una aplicación por analogía de los criterios formulados por el Grupo de Trabajo en el asunto Ajustes Fiscales en Fronteras de 1970. 
mier diferendo Atún-Delfín ${ }^{25}$. Así, en el segundo diferendo Atún-Delfín, el Grupo Especial dejó establecido en su informe que el artículo III del GatT "calls for a comparison between the treatment accorded to domestic and imported like products, not for a comparison of the policies or practices of the country of origin with those of the country of importation" (párrafo 5.8). Dado que la posición asumida por los paneles coloca a priori y de manera indiscriminada a todas las prohibiciones de importación relativas a los PMP en situación de conflicto con el régimen general del GATT, la única vía para justificarlas sería la del artículo XX. Esto significa que el Estado que las adopta tendría que respetar las rigurosísimas exigencias consagradas en esta norma si desea tomar medidas internas que regulan los PMP y que afectan el comercio de ciertos productos.

\section{ANÁLISIS CRÍTICO DE LAS DECISIONES ATÚN-DELFÍN}

La posición asumida por los paneles de los casos Atún-Delfín suscitó agudas críticas de un sector de la doctrina, desde una perspectiva que se sitúa cronológicamente antes de la creación de la omc (GATT de 1947). En la primera sección (A) presentamos una síntesis de estas. Sin embargo, el contexto normativo del GatT de 1994

25 En este caso, Holanda y la Comunidad Europea cuestionaban medidas relacionadas con la aplicación de la MMPA, las cuales comportaban un embargo que afectaba a los países que jugaban el papel de intermediarios en el comercio del atún. Estados Unidos decidió prohibir la importación de atún de los países intermediarios que no pudiesen probar que no habían comprado atún proveniente de países impedidos de exportar dicho producto a Estados Unidos, por no cumplir los requisitos impuestos en virtud de la MMPA. y, más precisamente, el principio de desarrollo sostenible, obligan al intérprete a una lectura renovada del artículo III, que tome distancia de la interpretación restrictiva de la que fue objeto en los mencionados diferendos (B). En esta sección demostraremos que, como consecuencia de tal lectura, la licitud de las medidas que tienen por objeto asegurar el respeto de los derechos laborales y que implican restricciones al comercio de productos fabricados violando dichos derechos, debe ser evaluada a la luz del artículo III del GATT y no del artículo XI.

\section{A. Debilidades de las decisiones Atún-Delfín en el marco del GATT de 1947}

Tomando como punto de partida el exhaustivo análisis de los informes Atún-Delfín realizado por Fernández (2008)' presentamos brevemente algunas críticas relativas a dichos informes, las cuales se insertan dentro de una exégesis de las disposiciones del GatT de 1947 y, por ende, se encuentran desprovistas de referencias al Acuerdo de Marrakech y el principio de desarrollo sostenible, aspecto que será objeto de la sección II-B. Dicho esto, es menester resaltar, en primer lugar, que los informes de los grupos especiales tienen como argumento central una interpretación restrictiva del artículo III del GATT, que se sustenta en la ausencia de mención explícita en dicho artículo respecto de las medidas relativas a los PMP. En segundo lugar, es preciso también abordar la errónea referencia al informe del Grupo de Trabajo en el asunto Ajustes Fiscales en Fronteras, de 1970. 
En lo que se refiere al primer aspecto mencionado en el párrafo precedente, compartimos plenamente la opinión de Fernández (2008) en el sentido de que la interpretación restrictiva del artículo III del GATT, en particular de la utilización mecánica e irreflexiva del término "producto" no es, en sí misma, un argumento suficiente para excluir las medidas relativas a los PMP del campo de aplicación de este artículo. Indudablemente, el empleo profuso de la palabra "producto" en el texto del artículo III es una consecuencia inevitable del hecho que el GatT es un acuerdo que porta sobre el comercio de mercancías y no, por ejemplo, de servicios. No existe en el texto del artículo III ningún elemento que indique de manera convincente que las partes quisieron excluir de su ámbito de aplicación las medidas relativas a los procesos y los métodos de producción (MRPMP). En tal sentido, Howse y Regan (2000, p. 254) afirman acertadamente que "the repeated reference to 'products' tells us nothing about de the product/process distinction. It merely reflects the fact that GATT is about trade in goods, not about trade in services or the movement of capital or labour".

Por otro lado, retomando las ideas de Howse y Regan (2000), también disentimos de la interpretación del artículo III del GATT formulada por el Grupo Especial, porque esta no guarda armonía con el sentido corriente de la frase del primer párrafo del artículo III, completado por la Disposición Suplementaria relativa a "las leyes, reglamentos y prescripciones que afecten a la venta... de productos en el mercado interior". Así, cualquier medida relativa al proceso de fabricación de un producto que tenga efectos comerciales restrictivos, aún cuando dicho proceso no tenga efectos tangibles en las características físicas del producto tiene, de una u otra manera, repercusiones en la venta de este en el mercado interno. Esta constatación debería bastar para que una medida de ese tipo, cuyo respeto es verificado en el momento de la importación del producto, sea incluida en el ámbito de aplicación del artículo III del GatT. En opinión de Howse y Regan (2000, p. 254), “[w]ho would doubt that, giving terms their ordinary meaning, process-based measures "affect the sale of products?". Es a todas luces evidente que una medida como la adoptada por Estados Unidos y contestada por México, que implica la restricción del comercio externo e interno de atún pescado con métodos que ponen en peligro a los delfines, tendrá consecuencias sobre el precio y la cantidad de atún comprado al exterior, tal como los antes citados juristas lo señalan.

Evocando argumentos análogos, Pauwelyn (2003) también cuestiona que los grupos especiales de los casos Atún-Delfín I y II se rehúsen a reconocer que una medida que tiene que ver con los pMp de los productos que se comercializan en su territorio, importados o nacionales, debe ser considerada como una medida aplicable a los productos importados según el texto de la Disposición Suplementaria del artículo III del GATT. De acuerdo con el argumento esgrimido por este autor, la posición de los grupos especiales comporta una prohibición drástica per se de aquellas medidas reglamentarias que no toman en cuenta las características físicas del producto pero que, sin embargo, son susceptibles de tener repercusiones en la venta del pro- 
ducto importado. Conforme a lo señalado por el autor mencionado, existe, pues, un divorcio entre la posición asumida por los grupos especiales y el sentido ordinario del artículo III y su Disposición Suplementaria. En buena cuenta, los grupos especiales introducen un nuevo criterio, ajeno a su sentido corriente, para aceptar o descartar la aplicación del artículo III. Así, según el cuestionado razonamiento de los grupos especiales, el artículo III será aplicable si la medida discutida toma en cuenta elementos vinculados a las características físicas del producto; pero deberá ser excluido si la medida incluye en el supuesto de hecho que la genera cuestiones relacionadas con los PMp que no tienen repercusión en las características del producto, aun cuando tenga efectos sobre su comercialización.

Respecto al argumento relativo al informe del Grupo de Trabajo en el asunto Ajustes Fiscales en Fronteras de 1970 cabe resaltar que detrás de la decisión de este panel, consistente en limitar los ajustes fiscales a los productos finales, se encontraba la voluntad de impedir que, por razones de orden tributario, los productos importados lleguen al mercado nacional en mejor posición respecto de los productos similares nacionales, pero sin tener que soportar cargas fiscales del país importador que no inciden directamente sobre los productos, como es el caso de las contribuciones a la seguridad social pagadas por los empleadores. Por tal motivo, nos parece inapropiado extrapolar los criterios de este grupo de trabajo, referidos a los ajustes fiscales a la frontera que conciernen el artículo
III:2 del GATT al caso del diferendo Atún-Delfín, el cual trata de medidas relativas a los PMP que tienen una incidencia en la venta del producto y que, por lo mismo, guardan relación directa con el artículo III: 4. En tal sentido, convenimos con Fernández (2008) que las medidas relativas a los PMP y las cargas fiscales aplicables en el país importador son dos cuestiones diferentes, regidas por normas específicas, esto es, los artículos III: 2 y III: 4 del GATT.

La explicación más plausible para entender la exclusión de las prohibiciones a la importación relativas a los PMP del ámbito de aplicación del artículo III, por parte de quienes redactaron los informes Atún-Delfín, pareciera residir en factores que, en el contexto nacional, serían catalogados como "razones de política judicial". Con gran perspicacia, Jackson (2000) sostiene que el siguiente párrafo del informe del Grupo Especial del caso Delfín-Atún I es bastante revelador en ese sentido:

These considerations led the Panel to the view that the adoption of its report would affect neither the rights of individual contracting parties to pursue their internal environmental policies and to cooperate with one another in harmonizing such policies, nor the right of the conTRACTING PARTIES acting jointly to address international environmental problems which can only be resolved through measures in conflict with the present rules of the General Agreement (párrafo 6.4).

Jackson propone, muy acertadamente, que el párrafo precedente podría ser reformulado en los siguientes términos: 
We recognize that there is a problem about how the environment and the process question relate and how process characteristics should be applied in this context. We don't think it's appropriate for us in our role as a Panel or 'judicial tribunal' to solve that. This really should be solved by the negotiators in a variety of possible formats. (Jackson, 2000, p. 305).

Consideramos bastante plausible la hipótesis de Jackson en el sentido de que el Grupo Especial quiso cerrar completamente la puerta a cualquier posibilidad de "activismo judicial" en materia ambiental, y prefirió dejar en las manos de las partes la responsabilidad de armonizar la liberalización del comercio con los imperativos ligados a la protección del medio ambiente. Dicho sea de paso, al hacer esto, el Grupo Especial dejó también al margen del régimen general del GATT a las medidas de naturaleza laboral que impliquen una prohibición de importación de productos fabricados en contravención de los derechos de los trabajadores, puesto que según el criterio adoptado, en tanto están referidas a Ios PMP, ese tipo de medidas debe ser también proscrito como consecuencia de la aplicación del artículo XI del GATT. Como lo demostraremos en la sección II-B, las conclusiones de los informes de los grupos especiales en los casos AtúnDelfín, en lo que se refiere a la relación entre las medidas referidas a los PMP y el artículo III deberían haber sido radicalmente diferentes en el contexto normativo del GATT de 1994.

\section{B. Las decisiones Atún-Delfín a la luz del principio de desarrollo sostenible en el marco del GATT de 1994}

Como es sabido, el Acuerdo de Marrakech no solamente constituye el tratado constitutivo de la omc, sino también la piedra angular de su sistema jurídico y del contexto normativo al cual están vinculados todos los acuerdos suscritos en el marco de esta organización internacional. A partir del $1^{\circ}$ de enero de 1995 el GatT quedó integrado dentro de dicho marco en calidad de acuerdo anexo, siendo considerado como un tratado erga omnes partes, es decir, aplicable a todos los Estados miembros de la omc. El momento de la integración del GATT en la omc marca un antes y un después en la vida de este tratado. En la actualidad, toda referencia al GATT debe entenderse hecha al GATT de 1994, y no al Ilamado GATT de 1947. El GATT de 1994 constituye una versión perfeccionada del GATT de 1947, en el sentido que aquel retoma prácticamente el texto integral de este último, pero con ciertas enmiendas destinadas a subsanar algunas omisiones y precisar ciertos puntos que fueron considerados conflictivos en el pasado (Fernández Rosas, 2010).

Partiendo de la premisa de que el contexto normativo del GATT de 1994 presenta, sin lugar a dudas, diferencias importantes respecto del contexto normativo del GATT de 1947, cabe preguntarse si, haciendo abstracción de las críticas antes formuladas respecto de los informes especiales, las conclusiones de los grupos especiales de los casos Atún-Delfín hubieran sido las mismas, si la lectura del artículo III del GatT se 
hubiese realizado a la luz de lo establecido en el preámbulo del Acuerdo de Marrakech; más precisamente, si la interpretación de dicho artículo hubiera tenido lugar tomando en cuenta el principio de desarrollo sostenible contemplado en este. Dado que la originalidad de nuestra crítica a las decisiones recaídas en los casos AtúnDelfín reside en la invocación del mencionado principio en el momento de la interpretación de las disposiciones del GATT, resulta imprescindible enunciar su contenido antes de explayarnos en el desarrollo de esta sección.

El principio en cuestión fue definido inicialmente en el ya célebre Informe Brundtland como "[d]evelopment that meets the needs of the present without compromising the ability of future generations to meet their own needs" (capítulo 2, párrafo 1). En el mismo informe se especifica que "[d]evelopment involves a progressive transformation of economy and society" (capítulo 2, párrafo 3). Asimismo, se reconoce que el desarrollo y el crecimiento económico son compatibles "provided the content of growth reflects the broad principles of sustainability and non-exploitation of others" (capítulo 2, párrafo 6), una constatación susceptible de generar importantes repercusiones en el campo social, puesto que la noción de desarrollo sostenible, conforme es entendida hoy en día, rebasa los límites de las cuestiones ambientales y tiende a incluir aspectos ligados a la protección y a la promoción de la dignidad humana. Para cierto sector de la doctrina, el principio de desarrollo sostenible habría ya alcanzado el estatus de norma consuetudinaria de derecho internacional. Por ejemplo, según Bothe, “[t]he principle of sustainable development is enshrined in so many laws and treaties that one can hardly doubt its character as being a rule of general international law" (2006, p. 556) ${ }^{26}$.

A fin de dar respuesta a la interrogante planteada respecto de las consecuencias de una relectura del artículo III del GATT a la luz del principio de desarrollo sostenible ${ }^{27}$, previamente cabe recordar que, de acuerdo con la jurisprudencia de la OMc $^{28}$, en el momento de interpretar los acuerdos anexos al Acuerdo de Marrakech, entre los que se encuentra el GATT, el artículo 3(2) del Entendimiento relativo a las normas y procedimientos por los que se rige la solución de diferencias, conocido por las siglas ESD (entendimiento sobre solución de diferencias) o DSU (Dispute Settlement Understanding), remite al intérprete a la Convención de Viena sobre el derecho de los tratados. En virtud del artículo 31(1) de este instrumento, todo tratado debe ser interpretado de buena fe, según el sentido corriente que se debe atribuir a los términos del tratado, en su contexto y a la luz de su objeto y su fin. El artículo 32(2) de la misma convención considera dentro del contexto del tratado objeto de interpretación a "todo acuerdo que se refiera al tratado y haya sido concertado entre todas las

26 En el mismo sentido, Sands afirma que "[t]here can be little doubt that the concept of sustainable development has entered the corpus of international costumary law" (2003, p. 254).

27 Una relectura que permitiría incluir en el ámbito de aplicación del artículo III, y no del artículo XI, medidas comerciales que comportan la prohibición de importar bienes fabricados por trabajadores cuyos derechos son vulnerados.

28 Podemos citar como precedente el informe del Órgano de Apelación emitido en el marco del diferendo Estados Unidos - Pautas para la gasolina reformulada y convencional. 
partes con motivo de la celebración del tratado". El mismo artículo incluye, dentro del contexto a ser considerado en el proceso hermenéutico, al preámbulo del tratado objeto de interpretación. Por todo ello, resulta comprensible que, en la práctica, el Órgano de Apelación de la omc tome en cuenta al preámbulo de la omc en el momento de interpretar las reglas del GATT ${ }^{29}$.

Ahora bien, con miras a poder comprender la influencia que el principio de desarrollo sostenible estaría llamado a ejercer en el momento de interpretar el artículo III del GATT, debemos remitirnos al segundo párrafo del preámbulo del Acuerdo de Marrakech:

Reconociendo que sus relaciones en la esfera de la actividad comercial y económica deben tender a elevar los niveles de vida, a lograr el pleno empleo y un volumen considerable y en constante aumento de ingresos reales y demanda efectiva y a acrecentar la producción y el comercio de bienes y servicios, permitiendo al mismo tiempo la utilización óptima de los recursos mundiales de conformidad con el objetivo de un desarrollo sostenible y procurando proteger y preservar el medio ambiente e incrementar los medios para hacerlo, de manera compatible con sus respectivas necesidades e intereses según los diferentes niveles de desarrollo económico. (El subrayado es nuestro).

De este párrafo se colige, según lo han dejado sentado los Estados miembros de la omc, que la liberalización del comercio internacional no constituye un fin en sí mismo, sino que está

Tal fue la conclusión a la que llegó el Órgano de Apelación en el diferendo Estados Unidos - Prohibición de las importaciones de determinados camarones y productos del camarón. orientada al logro de objetivos de naturaleza económica, social y ambiental, subsumidos en la noción de desarrollo sostenible.

El compromiso de los Estados miembros de la omc respecto de la realización del objetivo de desarrollo sostenible fue reiterado ulteriormente con motivo de la Conferencia Ministerial de DOHA, en el año 2001. Así, en el parágrafo de dicha declaración, los Estados miembros anuncian:

Reafirmamos decididamente nuestro compromiso con el objetivo del desarrollo sostenible, enunciado en el preámbulo del Acuerdo de Marrakech. Estamos convencidos de que los objetivos de respaldar y salvaguardar un sistema multilateral de comercio abierto y no discriminatorio y de actuar para la protección del medio ambiente y la promoción del desarrollo sostenible pueden y deben apoyarse mutuamente.

De otro lado, en el mismo acápite, los Estados miembros señalan que "no deberá impedirse a ningún país que adopte medidas para la protección de la salud y la vida de las personas y los animales o la preservación de los vegetales, o para la protección del medio ambiente, a los niveles que considere apropiados".

No menos importante es el hecho de que el Órgano de Apelación ha tenido la ocasión de poner de relieve que la consagración del objetivo de desarrollo sostenible en el preámbulo del Acuerdo de Marrakech impide que dicho principio sea soslayado en el momento de interpretar las disposiciones del GatT. Así, en el párrafo 129 de su informe sobre el diferendo Camarones-Tortugas se lee: 
El intérprete de tratados debe leerlos a la luz de las preocupaciones contemporáneas de la Comunidad de naciones por la protección y conservación del medio humano. Aunque el artículo XX no fue modificado en la Ronda Uruguay, el preámbulo del Acuerdo sobre la oMc revela que los firmantes de ese Acuerdo eran plenamente conscientes en 1994 de la importancia y legitimidad de la protección del medio ambiente como objetivo de la política nacional e internacional.

Esta constatación llevó al Órgano de Apelación a contemplar dentro del campo de aplicación del artículo XX (g), relativo a la protección de los "recursos naturales", a las tortugas, animales que fueron considerados "recursos vivos". De esta manera dejó abierta la puerta no solamente para que, en el marco del proceso interpretativo, el principio de desarrollo sostenible informe la lectura de las reglas del GATT, sino también para que el contenido de dicho principio reciba la influencia de las preocupaciones contemporáneas de la comunidad internacional, entre las cuales se encuentra la preservación del medio ambiente al igual que la protección de los derechos humanos, tanto políticos y civiles como sociales (categoría a la que pertenecen los derechos laborales) y económicos. Esta nueva perspectiva ha sido calificada por algunos autores como la "interpretación evolutiva" de los acuerdos anexos a la omc (Blackett, 1999; Baroncini, 2003), la cual, según confirma Cleveland (2001), crea un espacio en el sistema jurídico de la omc que conduce a la inclusión de aspectos relativos a los derechos humanos. De acuerdo con esta misma autora, este enfoque permitiría a dicho sistema, de manera concomitante, una adapta- ción flexible y progresiva que tenga en cuenta la transformación del derecho internacional.

A nivel doctrinario, Qureshi sostiene acertadamente que la noción de desarrollo sostenible está llamada a jugar un rol de primer orden en el proceso de interpretación de las reglas de derecho internacional económico:

Once development has been recognised in a trade agreement, its dye is cast deeper than other colours. Development is so fundamental a concept in international economic relations and law, that once it is taken into account, it must have a profound impact among the palette of colours. Its colour can, therefore, be coherently and harmoniously taken into account only by recognising its significance as an important informing agent in the process of interpretation. (2006, p. 142).

En el mismo sentido Kieffer, autor que considera que el principio de desarrollo sostenible ha alcanzado el estatus de norma consuetudinaria de derecho internacional, afirma que "[I] e droit de l'omc dans son ensemble doit... être interprété à la lumière du principe de développement durable" (2008, p. 193). Por su parte, Voigt pone de relieve el potencial del principio de desarrollo sostenible como punto de confluencia del sistema jurídico de la omc con otras ramas del derecho internacional cuando afirma que "[s]ustainable development as enshrined in wTO law requires the interpretation of trade law in the ligth of concerted bilateral or multilateral action to protect other interests than solely trade interests" (2009, p. 143). Esto implica, en primer lugar, que entre todos los significados 
susceptibles de ser atribuidos a una regla del GATT, se deberá dar preferencia al sentido que guarda armonía con la realización del principio de derecho sostenible; y, en segundo lugar, que el intérprete buscará evitar situaciones de antinomia normativa respecto de otras reglas de derecho internacional vinculadas con la realización del principio que nos ocupa. En este punto conviene recordar que el Órgano de Apelación dejó sentado en el caso Gasolina que el texto del GatT no debería ser leído aislándolo clínicamente del derecho internacional público ${ }^{30}$.

En lo que se refiere a la armonización de las normas del sistema de la omc con el sistema normativo de derecho internacional, en el marco de la realización del principio de derecho sostenible, resulta primordial evocar la naturaleza multidimensional de dicho principio, la cual ha sido reconocida en diversos instrumentos internacionales. A título de ejemplo podemos mencionar que en el seno de la Asamblea General de la onu, los Estados miembros se comprometieron, en la Cumbre Mundial del año 2005, a promover "la integración de los tres componentes del desarrollo sostenible -desarrollo económico, desarrollo social y protección del medio ambiente- como pilares interdependientes que se refuerzan mutuamente". En el mismo sentido, otro organismo del sistema de Naciones Unidas, la Organización Internacional del Trabajo, adoptó la Declaración de la olt sobre la justicia so-

30 Se trata de otra consecuencia de gran importancia de la referencia hecha por el Dsu al artículo 31 de la Convención de Viena. En virtud del artículo 31 (3) (c) de este acuerdo, la interpretación de un tratado debe tener en cuenta "toda norma pertinente de derecho internacional aplicable a las relaciones entre las partes." En tal facultad, el GATT posee un contexto externo constituido por las otras reglas y principios de derecho internacional. cial para una globalización equitativa, en cuyo preámbulo se anuncia que "los valores fundamentales de libertad, dignidad humana, justicia social, seguridad y no discriminación son esenciales para un desarrollo y una eficacia sostenibles en materia económica y social". No es de sorprender entonces que, a nivel de la doctrina, autores como Arbour y Lavallé (2006) afirmen que la adhesión al principio de desarrollo sostenible por parte de los Estados miembros de la omc revela su voluntad de conciliar tres términos que están inextricablemente ligados entre sí: desarrollo económico, calidad del medio ambiente y justicia social. Por todo ello, la noción de desarrollo sostenible puede también ser considerada un punto de confluencia de distintas ramas del derecho internacional como, por ejemplo, el derecho internacional del comercio, el derecho ambiental, el derecho internacional de los derechos humanos o el derecho internacional del trabajo; una constatación importante que deberá ser tomada en cuenta en el momento de interpretar el artículo III del GATT.

Dado que nuestro tema de investigación está ligado a la cuestión de la armonización del derecho internacional del comercio con el respeto de los derechos fundamentales de los trabajadores, debemos precisar que la realización del principio de desarrollo sostenible no puede ser disociada del respeto de los derechos humanos, incluidos aquellos de naturaleza socioeconómica. Esta constatación es ampliamente compartida por la doctrina. Así, por ejemplo, Meron (2003, p. 426) afirma de manera categórica que: 
[t]he concept of 'sustainable development', whose primary objective was the protection of the environment, has grown out of its ecological mould to encompass a comprehensive notion of development, which includes several human rights aspects.

Por su parte, Sedjari (2008) sostiene que el principio de desarrollo sostenible tiene un significado bastante amplio y que este impone el respeto de los derechos fundamentales, de naturaleza económica, social y cultural. Es más, el vínculo entre la noción de desarrollo sostenible y los derechos humanos ha sido reconocido por la International Law Association, en la Declaración de Nueva Delhi sobre los principios de derecho internacional relativos al desarrollo sostenible adoptada en el 2002. En el preámbulo de dicho documento los miembros de esta asociación declaran que, en su opinión, "the realization of the international bill of human rights, comprising economic, social and cultural rights, civil and political rights and peoples' rights, is central to the pursuance of sustainable development" ${ }^{31}$. De ello se desprende que la noción de desarrollo sostenible aparece como un punto de apertura dentro del sistema jurídico de la omc, respecto de cuestiones que atañen los derechos humanos y, por ende, los derechos laborales, entendiéndose que estos últimos son una subcategoría de los primeros.

Dicho esto, cabe recordar que todo Estado tiene la obligación de respetar, proteger y promover los derechos humanos (De Schutter, 2010). Ello

31 La Asociación de Derecho Internacional es una organización no gubernamental con estatuto consultivo ante algunos organismos especializados de las Naciones Unidas. implica una intervención gubernamental activa que puede traducirse en medidas reglamentarias y en políticas específicas en diversos campos, incluido el industrial. Con tal fin, se podrían adoptar medidas que atañen los métodos y procesos de producción como, por ejemplo, la prohibición de comercializar productos fabricados por personas en situación de trabajo forzoso o en condiciones que ponen en peligro la integridad física de menores de edad (Roux, 2010). La justificación de tales medidas sobre la base del principio de desarrollo sostenible se vuelve casi tautológica si evocamos las ideas de Pantano y Salomone, autores que abordan el problema del trabajo infantil y que nos recuerdan que "it is hard to maintain that the "objective of sustainable development' is alien to the protection of children's interest not to be employed in exhausting jobs during their earliest youth, in order to preserve their physical and psychological well-being and their right to education" (2008, p. 333).

En nuestra opinión, la exclusión de las medidas relativas a los PMP que implican una prohibición de importación del ámbito de aplicación del artículo III del GATT, conforme lo decidieron los grupos especiales de los casos Atún-Delfín I y II, resulta contradictoria con la relevancia acordada por los Estados miembros al principio de desarrollo sostenible y con la realización de los objetivos que este comporta. En efecto, como consecuencia de su consagración en el preámbulo del Acuerdo de Marrakech, la interpretación de dicho artículo, y de cualquier regla del GATT, debe estar orientada a la plena realización del mencionado principio y no a su menoscabo. 
En ese orden de ideas, resulta importante destacar que la reglamentación de los PMP guarda relación directa con el objetivo de desarrollo sostenible. Tan es así, que ese vínculo es reconocido de manera expresa por ciertas reglas de derecho positivo, como por ejemplo, el artículo 3(1)(a) de la Convención de Antigua ${ }^{32}$ :

"Sustainable development" means the process of progressive change in the quality of life of human beings, which places it as the centre and primordial subject of development, by means of economic growth with social equity and the transformation of methods of production and consumption patterns, and which is sustained in the ecological balance and vital support of the region. This process implies respect for regional, national and local ethnic and cultural diversity, and the full participation of people in peaceful coexistence and in harmony with nature, without prejudice to and ensuring the quality of life of future generations.

Por consiguiente, la transformación de los métodos de producción se presenta como una condición necesaria para la realización del objetivo de desarrollo sostenible, en todas sus dimensiones: ambiental, social y económica. Esto fue confirmado en el Plan de aplicación de las decisiones de la Cumbre Mundial sobre el DesarroIlo Sostenible, aprobado en Johannesburgo en el año 2002. En dicho documento se reconoce que "[p]ara lograr el desarrollo sostenible a nivel mundial es indispensable introducir cambios fundamentales en la forma en que producen y

32 Convention for Cooperation in the Protection and Sustainable Development of the Marine and Coastal Environment of the Northeast Pacific, del 18 de febrero del 2002. consumen las sociedades. Todos los países deben promover modalidades sostenibles de consumo y producción...".

¿Cómo promover entonces la realización del objetivo de desarrollo sostenible si no es a través de la transformación de los métodos de producción y, evidentemente, de la adopción de medidas que prevean y reglamenten tal evolución?, ¿por qué entonces promover una lectura del GATT que, como consecuencia de la exclusión del artículo III a favor del artículo XI, pone automáticamente en situación de ilicitud, respecto del régimen general, medidas relativas a los PMP que buscan la realización de unos de los objetivos fundamentales de los Estados miembros de la $\mathrm{OMc}$, so pretexto de que la medida no tiene repercusión en las características físicas del producto? Puesto que sin las medidas en cuestión no puede materializarse un desarrollo que tenga en cuenta el progreso económico, la protección del medio ambiente y la realización de la justicia social, resulta imperativo abandonar la interpretación restrictiva del artículo III del GATT utilizada por los grupos especiales de los casos Atún-Delfín I y II y llevar a cabo el proceso hermenéutico a la luz del principio de desarrollo sostenible. De no hacerse esto, se correría el riesgo de impedir que los Estados miembros de la omc puedan cumplir a cabalidad sus obligaciones internacionales ligadas al desarrollo sostenible, entre las que se encuentran el respeto, la protección y la promoción de los derechos humanos, incluidos los derechos de naturaleza laboral.

En este punto debemos insistir en lo ya señalado anteriormente, en cuanto a la obligación del 
intérprete de evitar toda situación de conflicto normativo entre el GATT y otras disposiciones de derecho internacional. Según Pauwelyn (2001), en la mayor parte de los casos es posible eludir tal tipo de antinomia puesto que las normas en cuestión están redactadas en términos bastante genéricos y, por ende, dan cabida a lecturas diversas. De acuerdo con este autor, una verdadera situación de conflicto solo podrá ocurrir cuando resulte imposible retener un sentido que asegure la coexistencia armoniosa de ambas reglas sin desnaturalizar la norma interpretada. De manera coincidente, Marceau (2002) también piensa que los acuerdos adscritos al sistema jurídico de la omc, como cualquier otro tratado, deben ser interpretados tomando en cuenta las demás normas de derecho internacional, aun cuando pertenezcan a ramas diferentes como, por ejemplo, los convenios que protegen los derechos humanos. Sobre la base de esta premisa, Marceau está convencida de que, en general, es de esperar que la interpretación de las normas de la omc se hagan en un sentido que permita y que promueva que los Estados miembros respeten todas sus obligaciones internacionales.

La interpretación del artículo III del GATT hecha por los paneles de los casos Atún-Delfín I y II no se condice con las ideas de Pawelyn y Marceau. Confrontados a una disyuntiva hermenéutica, los paneles optaron por una interpretación del artículo III que implicaba la restricción del ámbito de aplicación de esta norma y, como consecuencia de ello, una reducción del margen de maniobra de los Estados miembros en materia de reglamentación de los PMP. En efecto, considerar a priori toda prohibición de importación de bienes relativa a los PMP como contraria al artículo XI del GATT, y abstenerse de examinar la legalidad de la medida a la luz del artículo III, coloca ipso facto en una situación de impase a aquellos Estados que consideran necesaria la adopción de ese tipo de restricciones comerciales con miras a asegurar el respeto de normas que tienen por objetivo la plena realización del principio de derecho sostenible, incluida su dimensión social. ¿Qué pasaría, por ejemplo, si un Estado decidiese abolir la comercialización de mercancías en cuyo proceso de fabricación los obreros estuviesen expuestos a la inhalación de una substancia química cancerígena que no deja trazas detectables en la composición final de los productos? Si se asumiese la postura de los paneles Atún-Delfín I y II, dado que la substancia química no puede ser finalmente detectada en la mercancía la prohibición en cuestión debería ser considerada ilegal, en caso de que esta afectase a productos importados. En efecto, según los mencionados paneles, lo relevante, a efectos de la aplicación del artículo III no es la comparación de los procesos productivos, sino la de los productos finales. En buena cuenta, lejos de propiciar el respeto de las obligaciones a cargo del Estado inherentes a la realización del principio de desarrollo sostenible, el criterio de los paneles limita innecesariamente el margen de maniobra de los países miembros en este campo. Una lectura renovada del texto del GATT, especialmente de su artículo III, resulta ineludible en la nueva era del derecho internacional del comercio que 
comienza con el Acuerdo de Marrakech, sobre todo, si queremos evitar llegar a conclusiones que no guardan coherencia con los objetivos trazados por este tratado fundamental.

\section{CONCLUSIONES}

El presente artículo se sitúa en el marco del debate relativo a la interacción del sistema jurídico de la omc con otras normas de derecho internacional, particularmente aquellas que protegen los derechos laborales. Nuestro estudio forma parte de las tendencias doctrinarias que proponen una lectura de las normas de derecho internacional del comercio, que permita asegurar el pleno respeto de los derechos de los trabajadores. Asumiendo que una de las vías para alcanzar dicho objetivo podría ser la de las medidas comerciales, bajo la forma de prohibiciones a la importación de bienes producidos en contravención del derecho internacional del trabajo, el articulista identifica como uno de los principales obstáculos a la adopción de medidas de este tipo la postura asumida por cierta jurisprudencia relativa a la aplicación del GATT. En efecto, las decisiones Atún-Delfín I y II comportan una lectura estrictamente literal y restrictiva del GATT que busca evacuar del régimen general de este acuerdo toda consideración de naturaleza extra comercial. Como consecuencia de tal posición hermenéutica, las prohibiciones a la importación de bienes vinculadas a los PMP son rechazadas de plano sobre la base del artículo XI del GATT, sin que sea posible examinarlas dentro del marco del artículo III.
En caso de que se quisiese retomar el criterio que fluye de las decisiones Atún-Delfín I y II en diferendos en los que una de las partes conteste la validez de restricciones a la importación como las antes mencionadas, es altamente probable que la licitud de dichas medidas sería cuestionada en virtud del artículo XI del GATT. En ese caso, la única vía habilitante será la de las excepciones generales del artículo XX, lo que implica la aplicación del riguroso y difícilmente superable examen que acompaña la puesta en práctica de esta norma. Esto conlleva, en nuestra opinión, un camino tortuoso y lleno de obstáculos para la realización del principio de desarrollo sostenible. Una situación que no parece responder a las aspiraciones de los Estados miembros de la omc, conforme aparecen consignadas en el preámbulo del Acuerdo de Marrakech.

Tal como ha sido demostrado en este artículo, la criticable posición asumida por los grupos especiales en los diferendos Atún-Delfín, los cuales antecedieron la creación de la omc y de su sistema jurídico, parece difícilmente sustentable en la actualidad en el marco jurídico de esta organización internacional. Dos razones de peso sustentan la afirmación precedente. En primer lugar, si se toma en cuenta la jurisprudencia relativa al GATT de 1994, que reconoce el rol orientador del preámbulo del Acuerdo de Marrakech y el vínculo entre el derecho de la omc con el resto del derecho internacional, es innegable que el texto del GATT no puede ser leído de manera aislada, omitiendo su contexto normativo del cual forma parte el concepto multidimensional de desarrollo sostenible, ni ignorando las demás normas de derecho internacional ligadas a 
la realización de dicho principio. Es más, el mencionado preámbulo deja claramente sentado que la liberalización del comercio debe tender a elevar los niveles de vida de los países miembros. En segundo lugar, porque el objetivo del desarrollo sostenible no podrá materializarse a nivel mundial si los Estados miembros de la omc se encuentran severamente limitados en lo que se refiere a la adopción de medidas tendientes a conseguir la transformación de los métodos y procesos de producción imperantes. Dado que la noción de desarrollo sostenible no se limita a aspectos de orden ambiental, dichas medidas pueden también implicar la abolición de prácticas que vulneran los derechos fundamentales de la persona en el contexto de las relaciones laborales.

En 1994, el GATT fue injertado en un nuevo sistema jurídico, el de la omc, el cual afirma sin ambages su conexión con el resto del derecho internacional. Sostener hoy en día que el régimen general del GATT excluye consideraciones relativas a los procesos y los métodos de producción, por el simple hecho de que estos no tienen impacto en las propiedades físicas del producto, equivale a afirmar que estamos frente a un texto autárquico, desprovisto de cualquier vínculo con los objetivos que se dieron los fundadores del nuevo sistema de derecho internacional del comercio en el momento de la creación de la omc. En nuestra opinión, avalar tal posición no solamente contradice la letra y el espíritu del Acuerdo de Marrakech, sino que constituye una vuelta atrás en el reloj de la historia de la evolución del derecho internacional del comercio.
Bibliografía

Arbour, J. M. y Lavallé, S. (2006). Droit international de l'environnement. Cowansville. Canadá: Les Éditions Yvon Blais.

Baroncini, E. (2003). L'articolo XX GATT e i metodi di produzione non collegati ai prodotti. En L. Rossi (Ed.). Commercio internazionale sostenibile? wтo e Unione europea (pp. 51-75). BoIogna, Italia: Società Edictrice II Mulino.

Bhala, R. (2005). Modern gatt Law. A Treatise on the General Agreement on Tariffs and Trade. Londres, Reino Unido: Sweet \& Maxwell.

Blackett, A. (1999). Whither Social Clause?: Human Rights, Trade Theory and Treaty Interpretation. Columbia Human Rights Law Review, 31(1), 2-80.

Bothe, M. (2006). Whose environment? Concepts of commonality in international environmental law. En G. Winter (Ed.). Multilevel Governance of Global Environmental Change (pp. 539-558). Cambridge, Reino Unido: Cambridge University Press.

Cleveland, S. (2001). Human Rights Sanctions and the World Trade Organization. En F. Francioni (Ed.). Environment, Human Rights and International Trade (pp. 199-261). Portland, Estados Unidos: Hart Publishing.

Comisión Mundial sobre el Medio Ambiente y el Desarrollo de la Organización de las Naciones Unidas. Nuestro futuro común. Doc. off. AG NU, $42^{\mathrm{e}}$ sess., supp. $\mathrm{n}^{\circ} 25$, Doc. NU 
A/42/25 (1987). Recuperado de http://conspect.nl/pdf/Our_Common_Future-Brundtland_Report_1987.pdf

De Schutter, O. (2010). International Human Rights Law. Cambridge, Reino Unido: Cambridge University Press.

Denkers, J. (2008). The World Trade Organization and Import Bans to Violations of Fundamental Labour Rights. Amberes, Oxford y Portland, Bélgica, Reino Unido y Estados Unidos: Intersentia.

DiTuri, C. (2007). Globalizzazione delle'economia e diritti umani fondamentali in materia di lavoro: il ruolo dell'OIL et dell'OMC. Milán, Italia: Giuffrè Editore.

Fernández Egea, R. (2008). Comercio de mercancías y protección del medio ambiente en la oмc. Madrid, España: Marcial Pons.

Fernández Rosas, J. (2010). Sistema de derecho económico internacional. Madrid, España: Civitas.

Francioni, F. (2006). wTo law in context: the integration of international human rights and environmental law in the dispute settlement process. En G. Sacerdoti, A. Yanovich et J. Bohanes (Eds.). The wTo at Ten. The Contribution of the Dispute Settlement System (pp. 143-154). Cambridge, Reino Unido: Cambridge University Press.

Giansanti, A. (2008). La tutela di interessi non economici nel sistema omc. Ambiente, salute dei consumatori e "core labour standards" nel diritto del commercio internazionale. Nápoles, Italia: Editoriale Scientifica.

Grupo de Trabajo del GatT de 1947. (1970). Ajustes fiscales en frontera. Adoptado el 2/12/1970, IBDD 18S/106.

Grupo Especial del GATT de 1947. (1991). EE. UU.-Restricciones a la importación del atún y productos derivados, no adoptado y distribuido el 3/9/1991, IBDD 39/S/183.

Grupo Especial del GatT de 1947. (1994). EE. UU. Restricciones a la importación del atún y productos derivados, no adoptado y distribuido el 16/6/1994, DS29/R.

Guzmán, A. y Pauwelyn, J. (2009). International Trade Law. Austin, Boston, Massachusetts, Estados Unidos: Aspen Publishers.

Hepple, B. (2005). Labour Laws and Global Trade. Oxford, Portland, Oregon: Hart Publishing.

Howse, R. y Regan, D. (2000). The Product/Process Distinction - An Illusory Basis for Disciplining 'Unilateralism' in Trade Policy. European Journal of International Law, 11(2), 249-289.

Jackson, J. (1997). The World Trading System. Law and Policy of International Economic Relations. Cambridge, Massachusetts, Estados Unidos: The MIT Press. 
Jackson, J. (2000). Comments on Shrimp/Turtle and the Product/Process Distinction. European Journal of International Law, 11(2), 303-307.

Kieffer, B. (2008). L'Organisation mondiale $d u$ commerce et l'évolution du droit international public. Bruselas, Bélgica: Larcier.

López Jurado, C. y Martín, P. (2010). La regulación material del comercio internacional. En L. Hinojosa y J. Roldán (Eds.). Derecho internacional económico (pp. 97-120). Madrid, España: Marcial Pons.

Luff, D. (2004). Le droit de l'Organisation mondiale du commerce. Bruselas, Bélgica: Bruylant.

Marceau, G. (2002). wto Dispute Settlement and Human Rights. European Journal of International Law, 13(4), 753-814.

Mavroidis, P. (2007). Trade in Goods. The GATT and the Other Agreements Regulating Trade in Goods. Oxford, Reino Unido: Oxford University Press.

Mehmet, O., Mendes, E. y Sinding, R. (1999). Towards a Fair Global Labour Market: Avoiding a New Slave Trade. Londres, Reino Unido: Routledge.

Meron, T. (2003). International Law in the Age of Human Rights: General Course on Public International Law. R.C.A.D.I. 2003(301), 9-489.
Musselli, I. (2001). Alla ricerca di un difficile equilibrio tra commercio e diritti sociali: la nozione di "similarità" dei prodotti ex art. III del GatT. Diritto del commercio internazionale, 15(4), 873-891.

Órgano de Apelación de la omc (2001). Informe CE-Medidas que afectan al Amianto y los productos que contienen amianto, adoptado el 12/03/2001, DS135.

Órgano de Apelación de la omc. (1987). Informe Japón - Impuesto sobre las bebidas alcohólicas, adoptado el 10/11/1987, IBDD 34S/83.

Órgano de Apelación de la omc. (1996). Informe Estados Unidos - Pautas para la gasolina reformulada y convencional, adoptado el 29/4/1996, WT/DS2/AB/R.

Órgano de Apelación de la omc. (1998). Estados Unidos - Prohibición de las importaciones de determinados camarones y productos del camarón, adoptado el 12/10/1998, WT/ DS58/AB/R.

Pantano, F. y Salomone, R. (2008). Trade, ILO Child Labour Standards and the Social Clause: Definitions, Doubts and (Some) Answers. En G. Nesi, L. Nogler y M. Pertile (Eds.). Child Labour in a Globalized World: A Legal Analysis of ILO Action (pp. 323-346). Hampshire, Reino Unido: Ashgate.

Pauwelyn, J. (2001). The Role of Public International Law in the wTo: How far can We go? 
The American Journal of International Law, 95, 535-578.

Pauwelyn, J. (2003). Conflicts of Norms in Public international Law. How wTo Law Relates to Other Rules of International Law. Cambridge, Reino Unido: Cambridge University Press.

Pauwelyn, J. (2005). Rien ne va plus? Distinguishing domestic regulation from market access in GATT and GATS. Minnesota Journal of Global Trade, 4(2), 131-170.

Picone, P. y Ligustro, A. (2002). Diritto dell'Organizzazione mondiale del commercio. Padua, Italia: CEDAM.

Qureshi, A. (2006). Interpreting wто Agreements. Problems and Perspectives. Cambridge, Reino Unido: Cambridge University Press.

Roux, D. (2010). Le 'droit à un travail décent' affirmé dans les normes internationales de I'ONU et de I'OEA. Ou la longue marche d'un vieux couple : le droit du travail et les droits de la personne. En P. Verge (Ed.). Droit international du travail. Perspectives canadiennes (pp. 143-221). Cowansville, Canadá:
Éditions Yvon Blais.

Salmon, J. (2001). Dictionnaire de droit international public. Bruselas, Bélgica: A.U.F.

Sands, P. (2003). Principles of International Environmental Law. Cambridge, Reino Unido: Cambridge University Press.

Sedjari, A. (2008). Gouvernance des droits de l'homme et centralité humaine du développement. En A. Sedjari (Dir.). Droits de l'homme et développement durable. Quelle articulation? (pp. 17-25). Rabat, Marruecos: L'Harmattan.

Van den Bossche, P., Schrijver, N. y Faber, G. (2007). Unilateral Measures adressing non-Trade Concerns. A study on wTo Consistency, Relevance of other International Agreements, Economic Effectiveness and Impact on Developing Countries of Measures concerning Non-Product-Related Processes and Production Methods. La Haya, Holanda: Ministerio de Relaciones Exteriores.

Voigt, C. (2009). Sustainable Development as a Principle of International Law. Leiden, Holanda: Martinus Nijhoff Publishers. 